\title{
$\bullet \cdot$ \\ The Use of a Halo - Vest for the Upper Cervical Spine Injuries
}

IJCRR

Section: Healthcare

ISI Impact Factor

(2019-20): 1.628

IC Value (2019): 90.81

\section{Quziev Ortiqsher Ilmiddinovich ${ }^{1}$, Ismoilova Muazzam Isroilovna ${ }^{1}$}

$\operatorname{SJIF}(2020)=7.893$

\author{
Fergana Branch Tashkent Medical Academy Uzbekistan, Ferghana, 150100.
}

(c) (i) (3)

Copyright@IJCRR

\section{ABSTRACT}

Introduction: In the structure of the cervical spine injury, upper cervical spine injuries occupy from 5.5 to $35 \%$ and 1 to $2 \%$ of all spinal injuries. The main task in their treatment is the prevention of secondary displacements if possible elimination of deformations and ensuring reliable stabilization.

Objective: Study of the effectiveness of the use of a halo - vest for the upper cervical spine injuries.

Methods: The results of closed reduction and rigid stabilization with the Halo - vest in 28 patients with injuries of the upper cervical spine at the Fergana branch of the Republican research centre of emergency medicine are discussed. The average age of the patients is 31 years. The observation period of patients is 3 months or more.

Result: In 4 (14.3\%) patients with C1 fracture, slight neck pain persisted. Full offset correction was achieved in $44.4 \%$ of cases. In all cases, there were no secondary displacements of bone fragments. The overall rate of healing after 90 days of Halo - vest is $89.3 \%$ traction. Complications were observed only in 1 (3.6\%) patient in the form of scalp soft tissue infection.

Conclusion: This method reduces the likelihood of postoperative complications due to low invasiveness, provides early verticalization and rehabilitation of patients.

Key Words: C1 and C2 fracture, Hangman's fracture, Odontoid fracture, Traumatic spondylolisthesis C2, Upper cervical spine injury, Use of the Halo - vest

\section{INTRODUCTION}

Traumatic injuries of the upper cervical spine include damage to the first two vertebrae and their ligamentous apparatus. In the structure of the cervical spine injury, these injuries occupy from 5.5 to $35 \%$ and 1 to $2 \%$ of all spinal injuries. The incidence of fractures of the odontoid process of the $\mathrm{C}_{2}$ is 4 to $25 \%$ of all injuries of the cervical spine. $\mathrm{C} 2$ arch fractures(Hangman's fracture) occur in $4-7 \%$ of cases. Multiple "bursting" fracture of the $\mathrm{C}_{1}$ (Jefferson fracture) occurs from 2 to $13 \%$ of all fractures of the cervical spine. Among the fractures of the upper cervical spine (UCS), Jefferson's fracture in combination with Hangman's fractures occurs in $6-26 \%$ of cases. Odontoid fractures are observed in $5-53 \%$ of cases of fractures of the craniovertebral level. ${ }^{1-4}$

Among the causes of traumatic injuries of the UCS are dominated by road accidents, falling head down, falling objects on the head, overturning over the head, a blow to the cervi- cal-occipital, frontal region, sudden rotational accelerations, etc. Until the mid-70s, the main method of treating traumatic injuries of $\mathrm{C}_{1}-\mathrm{C}_{2}$ was the method of immobilization of a thoracoacromial plaster cast, the imposition of which was preceded by traction with a Glisson loop, skeletal traction for the parietal tubercles, or the zygomatic arches. At the same time, it was not recommended to use forced distraction efforts, observing gradualism and caution. In unstable fractures in patients treated with this method, the incidence of post-traumatic deformities and chronic atlantoaxial dislocations reached $65 \%$. This method did not allow for long-term rigid fixation, dosed dynamic correction of the deformity. ${ }^{6-10}$

The main task in their treatment is the prevention of secondary displacements, elimination of deformations, if possible, and ensuring reliable stabilization. The problems of providing adequate care to patients with injuries of the upper cervical vertebrae are still relevant and far from a final solution.

\section{Corresponding Author:}

Quziev Ortiqsher, Ferghana region, Qodiriy street 18/49, Fergana, Uzbekistan.

Phone: +998902309968; Email: ortiqsher@mail.ru

ISSN: 2231-2196 (Print)

Received: 24.08 .2020
ISSN: 0975-5241 (Online)

Revised: 21.10 .2020
Accepted: 19.11 .2020
Published: 03.02 .2021 
This is indicated by the divergence of views in the choice of treatment tactics of individual specialists. ${ }^{4,5}$

\section{MATERIALS AND METHODS}

The analysis of the results of treatment of 28 patients with UCS injury for the period from 2012 to 2019 was carried out. in the emergency neurosurgical department of the Fergana branch of the Republican research centre of emergency medicine. Of these, $21(75.0 \%)$ were men, $6(25.0 \%)$ women. The age of the patients is from 18 to 72 years, the average age is $31( \pm 14.5)$ years. By the mechanism of injury, road traffic accidents prevailed - $18(64.3 \%)$ cases, less often falling from a height - $6(21.4 \%)$ and diving in shallow water - $4(14.3 \%)$.

Severe pain syndrome at rest ( 3 points on the W.W. Downie scale), or arising during light exercise (2 points on the Downie scale) were in $46.4 \%$ and $50.0 \%$ of patients, respectively. Mild neck pain (1 point on the Downie scale) was present in only $1(3.6 \%)$ patient with a type I odontoid fracture. Cervicalgia syndrome was more pronounced (3 points on the W.W. Downie scale - in $58.8 \%$ of patients) with odontoid fractures type II, which was due to a smaller contact area of the fragments and, accordingly, a greater tendency to displacement with the development of atlantoaxial dislocation. Less pronounced pain syndrome (2 points - in 66.7\%, 3 points - in 33.3\%) was typical for $\mathrm{C}_{1}$ fractures with displacement. The smallest clinical manifestations ( 2 points - in $80 \%$ of patients, 3 points - in 20\%) were in patients with Hangman's fracture.

The American Spine Injury Assosiation \International Standards for Neurological and Functional Classification of Spinal Cord Injury (ASIA \ISCSCI) scale (2015) was used to determine the functions of the spinal cord, according to international standards. In 24 (85.7\%) patients, the UCS fracture was uncomplicated (grade E on the ASIA scale). Grade B on the ASIA scale was in $1(3.6 \%)$ patient, grade $\mathrm{C}$ in $2(7.1 \%)$ cases, grade $\mathrm{D}$ in 1 (3.6\%) patient. ${ }^{11-14}$

The assessment of the severity of the condition and the neurological status was carried out at the time of admission, on the day of stabilization, in the dynamics of the postoperative period and on day 90. Upon admission, all patients with fractures of the UCS have performed a plain X-ray of the cervical spine in 2 projections and targeted radiography of the UCS in a transoral position. If the fracture of the odontoid process was verified by computer tomography (CT), radiography was performed for preoperative planning.

For victims of an accident or a fall from a great height (24 people $-85.7 \%$ ), first of all, CT of the cervical spine was performed. CT was also performed in patients after diving in shallow water, with clinical signs of cervical vertebra frac- ture, victims with impaired wakefulness, unknown traumatic history and trauma on the head, as well as suspected fractures according to X-ray examination methods.

In the postoperative period, radiography of the craniovertebral level was performed in all patients to control the correct placement of fixators and the degree of deposition of the dislocated atlantoaxial complex.

CT was performed in all $28(100 \%)$ patients. CT was used as a method of primary imaging in $24(85.7 \%)$ patients, after spondylography of UCS - in $4(14.3 \%)$ patients. X-ray examination revealed a $\mathrm{C}_{1}$ fracture in the first type in 1 (3.6\%) patient, in $3(10.7 \%)$ patients in the second type, and $2(7.2 \%)$ patients in the third type, with a total discrepancy of the lateral masses of the atlas more than $8.1 \mathrm{~mm}$ relative to the lateral masses of the axis.

According to the classification of injuries of the odontoid fractures according to Anderson and D'Alonzo (1974), type I was observed in $2(7.1 \%)$ patients, type II - in $10(35.7 \%)$, type III - in $5(17.9 \%)$. According to the X-ray classification of $\mathrm{C} 2$ arch fractures (according to the degree of displacement and angular deformity), the distribution was as follows:

Type I - bilateral separation of the arch from the $\mathrm{C}_{2}$, without displacement and angular deformity - $1(3.6 \%)$ patient;

Type II - fracture of both roots of the arches with a displacement of more than $3 \mathrm{~mm}$, with a slight angular deformation $-1(3.6 \%)$;

Type II-A - the fracture is similar to that of type II, but with the prevalence of pronounced angular deformity - 2 (7.1\%);

Type III - significant displacement and angular deformity of the $\mathrm{C}_{2}-1(3.6 \%)$;

Type IV - posterior displacement of the $\mathrm{C}_{2}$ body - there were no patients.

In $5(17.9 \%)$ patients with type II odontoid fractures, CT verified the high location of the fracture line, and therefore the examination was supplemented with Magnetic resonance imaging (MRI)of the cervical spine. In 2 cases, signs of damage to the transverse ligament of the atlas were revealed. MRI was also performed in 4 patients with concomitant type II and III $\mathrm{C}_{1}$ injuries, of which 1 patient had an injury of the transverse portion of the cruciate ligament. The integrity of the transverse portion of the cruciate ligament was one of the most important criteria in choosing a method for stabilizing the UCS. Also, using MRI, the degree of spinal cord injury was determined in patients with complicated UCS fracture (9 people - 32.1\%).

In $16(57.1 \%)$ patients, a concomitant injury was diagnosed. In 14 patients, a combination of Traumatic Brain Injury of varying severity with damage to the musculoskeletal system was revealed. Concussion or contusion of the brain and limb 
fractures prevailed. The hepatic rupture was verified in 1 patient, requiring surgery.

In the treatment of injuries of the UCS, we set the following tasks:

1) Achieving the maximum possible reconstruction of the damaged spine with the elimination of the compressing components that affect the neurovascular formations;

2) Restoration of stability at the level of damage, excluding the phenomenon of redislocation of injured segments;

3) The maximum preservation of the range of motion in the cervical spine after treatment;

4) Prevention of possible complications that may arise during treatment or in the long term.

The tasks are solved subject to the following principles of treatment:

1) The principle of maximum radicalism and simultaneity;

2) The principle of maximum minimally invasiveness;

3) The principle of maximum shortening of the time needed to achieve the final reconstruction;

4) The principle of ensuring the maximum possible comfort for the patient during treatment;

5) The principle of prevention of possible complications during treatment and after its completion.

Methods for the treatment of traumatic injuries of the segments of the craniovertebral junction are conventionally divided into 1) conservative - external immobilization, traction; 2) conditionally conservative - Halo - vest correction and stabilization; 3) surgical i.e. internal fixation.

Halo-vest was applied according to the standard technique, after which a dosed distraction was performed to eliminate the displacement of bone fragments.

The patients were transferred to an upright position on the first day after applying the apparatus. Control radiographs of the cervical spine were taken once every 4 weeks. Fixation in the Halo - vest lasted up to 3 - 4 months. After its removal, external fixation was performed with a removable head holder for $2-3$ months. The observation period of patients is 6 months or more.

\section{RESULTS}

To determine the results of the effectiveness of Halo- vest fixation and to assess its place in the complex treatment of UCS fractures, we compared the results of treatment based on the obtained X-ray and clinical data in patients before and after halo fixation. Clinical and radiological assessment was carried out immediately after the fracture healed and immobilization was stopped, one month after the union and then every 6 months
Pain syndrome at rest (3 points on the W.W. Downie scale), or arising during light physical exertion (2 points on the W.W. Downie scale) after removal of the Halo - vest was not noted. In 3 (10.7\%) patients with $\mathrm{C}_{1}$ fracture, mild neck pain (1 point on the W.W. Downie scale) remained (Table 1).

On control X-ray examination, complete correction of the displacement was achieved in $8(44.4 \%)$ cases, regression of displacement of varying severity - in $5(27.8 \%)$, a significant reduction was not achieved - in $2(11.1 \%)$, fixation in the achieved position was carried out in $3(16.7 \%)$ patients. In all cases, there were no secondary displacements of bone fragments of the $\mathrm{C}_{2}$.

All fractures of the ring and arch of the $\mathrm{C}_{1}$ were completely consolidated. With odontoid fractures type I, 100\%, type II $80 \%$ and type III $100 \%$ healed. With a fracture of the $\mathrm{C}_{2}$ arch (hangman's fracture), healing is $90 \%$. The overall rate of healing after 90 days of Halo - vest is $89.3 \%$ traction.

No worsening of symptoms was observed on dynamic neurological examination. In one patient with a neurological disorder according to the ASIA type B classification below the level of damage in the rehabilitation period, motor functions and muscle strength in the control groups recovered to 3 points.

Complications in the form of secondary mixing, pseudarthrosis, screw perforation, and intracranial hematoma were not observed. Only $1(3.6 \%)$ patient had an infection of the scalp soft tissues in the late period of Halo - vest traction, the apparatus was removed and further immobilization was performed with a removable head holder.

\section{DISCUSSION}

The problem of choosing the tactics of treating patients with fractures of the UCS has still not lost its relevance and is the subject of increased attention among neurosurgeons and traumatologists. Despite a large number of messages on the topic under study, many questions remain unsolved and are still far from a final solution. ${ }^{1,3,20}$

The disadvantages of the most commonly used structures for posterior occipito spondylodesis, cannulated screws for fixing the odontoid process of the axis, are an increased risk of deformity, migration of components of fixing structures, depending on the degree of activation of movements in the cervical spine, the need to immobilize 3-4 vertebrates motor segments. The number of intraoperative complications, according to some literature data, reaches $9-12 \%{ }^{16-18}$ and unsatisfactory results of surgical treatment in $18-29 \%$ of patients are due to secondary deformities with the development (aggravation) of neurological disorders due to incompetent spondylodesis, cicatricial adhesive processes, uncovertebral $\operatorname{arthrosis.~}^{10,15}$ 
In 2000, under the leadership of U. Vieweg ${ }^{20}$, a 40-year analysis of the treatment of 682 patients was carried out. The results of treatment with the help of the Halo - vest of fractures UCS were evaluated. The healing rate of all types of $\mathrm{C}_{1}$ vertebra fractures is $83 \%$, in our series $100 \%$. According to the author's data and in our study, recovery was noted in all types I and III odontoid fractures. When researching U. Vieweg type II fracture healing occurred $67 \%$, according to our data $80 \%$. Regarding the healing of fractures of the $\mathrm{C}_{2}$ arch, our data are close to those reported by U. Vieweg., ${ }^{2,7,8}$

In our material, possible complications of the apparatus method of treatment, such as the development of pressure ulcers in the places of pressure of the corset, difficulty in swallowing, pain and numbness in the hands, perforation with a screw of the skull bones with the formation of an epidural hematoma were not observed. Only $3.6 \%$ of patients had soft tissue inflammation in the area of cortical screws. ${ }^{19,20}$

The problem of surgical treatment of patients with complicated $\mathrm{C}_{1}$ and $\mathrm{C}_{2}$ vertebral dislocations has not been completely resolved to date. The advantage of the Halo - vest is to provide rigid fixation of the cervical spine in combination with the possibility of dynamic correction while maintaining the patient's mobility. ${ }^{18,19}$

\section{CONCLUSIONS}

The use of the Halo - vest allows rationally eliminating the displacement of bone fragments, restoring anatomical relationships in the craniovertebral region with simultaneous fixation of the cervical vertebrae and allows you to start early activation and rehabilitation of victims. Bony fusion succeeded in $89.3 \%$ of patients. A halo vest can be recommended for patients with Jefferson fractures, hangman's fractures and odontoid fractures with a dislocation rate.

\section{ACKNOWLEDGEMENT}

I deeply indebted to the Dr Urinboyev Baxtiyor Karimovich chairman of Department of Emergency Neurosurgery Fergana Branch Republican Research Centre of Emergency Medicine for his support. Author acknowledges the immense help received from the scholars whose articles are cited and included in references of this manuscript. The authors are also grateful to authors /editors/ publishers of all those articles, journals and books from where the literature for this article has been reviewed and discussed.

Conflict of Interest: The authors declare that there is no conflict of interest.

\section{Source of funding: Nil}

\section{REFERENCES}

1. Babkin AV. Diagnostics and treatment of injuries of the upper cervical vertebrae [dissertation]. Minsk, Belarus: 1997.

2. Kolesov SV. Old injuries of the ligamentous apparatus of the upper cervical region in children and adolescents [dissertation]. Moscow, Russia: 1992.

3. Lutsik AA, Ratkin IK, Nikitin MN. Craniovertebral injuries and diseases. Novosibirsk, Russia: 1998;552.

4. Nikitin MN. Damage to the I-II cervical vertebrae [dissertation]. Moscow. 1984.

5. Osna AI. Clinical manifestations of the treatment of craniovertebral lesions. Neurosurgical treatment of the consequences of craniovertebral lesions. Collection of scientific papers. Kemerovo, Russia; 1981:26-31.

6. Polishchuk NYe, Korzh VYa, Fischenko VYa. Spine and spinal cord injuries. Kiev, Ukraine: 2001;387.

7. Ratkin IK. Old complicated dislocations of the Atlanta, diagnosis and surgical treatment [dissertation]. Novokuznetsk, Russia: 1995.

8. Tsivyan YaL. Fractures of the II cervical vertebra and their treatment. J Bull Surg 1976; 117(7):57-63.

9. Cheremisin VM, Ishchenko BI. Emergency radiation diagnostics of mechanical damage. - Sankt Petersburg, Russia: Hippocrates; 2003:357.

10. Austin RC, Alexander JT. C2 Trauma. J Sem Neurosurg 2002;13;2:173-178.

11. Clark CR, White AA. Fractures of the dens: A multicenter study. J Bone Joint Surg 1985; 67:1340-1348.

12. Crawford NR, Hurlbert JR. Anatomy and Biomechanics of the Craniocervical Junction. J Sem Neurosurg 2002;13;2:101-110.

13. Dai LY, Yuan BN., Liu HK, Jia LS, Zhao DL. Surgical treatment of non-united fractures of the odontoid process, with special reference to occipito cervical fusion for nonreducible atlantoaxial subluxation or instability. J Eur Spine 2000;9:118-122.

14. Dickman CA, Hadley MN, Browner C, Sonntag VK. Neurosurgical management of acute atlas-axis combination fractures: A review of 25 cases. J Neurosurg 1989;70:45-49.

15. Greene KA, Dickman CA, Marciano FF, Drabier JB, Hadley $\mathrm{MN}$, Sonntag VK. Acute axis fractures: Analysis of management and outcome in 340 consecutive cases. J Spine 1997; 22:18431852.

16. Hadley MN. Isolated Fractures of the Axis in Adults. J Neurosurg 2002;50:125-139.

17. Imaizumi $\mathrm{T}$, Sohma $\mathrm{T}$, Hotta $\mathrm{H}$, Teto I, Imaizumi H, Kaneko M. Associated injuries and mechanism of atlanto-occipital dislocation caused by trauma. J Neurol Med Chir (Tokyo) 1995;35:385391.

18. Lennarson PJ, Mostafavi H, Traynelis VC, Walters BC. Management of type II dens fractures: A case-control study. J Spine 2000;25:1234-1237.

19. Pitzen T, Caspar W, Steudel WI., Barbier D. Dens fracture in elderly patients and surgical management. J Aktuelle Traumatol 1994;24:56-59.

20. Vieweg U, Schultheiss R. A review of halo vest treatment of upper cervical spine injuries. Arch Orthop Trauma 2001;121(12):50-55. 
Table 1: Comparison of pain intensity before and after halo fixation

\begin{tabular}{llccccc} 
Level and type of fracture & \multicolumn{3}{c}{ Intensity of pain in points } \\
& & Before treatment & \multicolumn{2}{c}{ After treatment } \\
Fracture of the C & 1 & 2 & 3 & 1 & 2 & 3 \\
I type & - & 4 & 2 & 3 & - & - \\
II type & - & 1 & & - & - & - \\
III type & - & 1 & 2 & 1 & - & - \\
Odontoid fracture & - & 1 & 1 & 2 & - & - \\
I type & 1 & 6 & 10 & - & - & - \\
II type & 1 & 1 & & - & - & - \\
III type & - & 2 & 8 & - & - & - \\
C2 arch fractures (hangman's fracture) & - & 3 & 2 & - & - & - \\
I type & - & 4 & 1 & - & - & - \\
II type & - & 1 & & - & - & - \\
II A type & - & 1 & & - & - & - \\
III type & - & 2 & & - & - & - \\
Total & - & & 1 & - & - & - \\
\hline
\end{tabular}

